\title{
Highly efficient enzymatic biodiesel production promoted by particle-induced emulsification
}

\author{
Juan Mangas-Sánchez ${ }^{*}$ and Patrick Adlercreutz
}

\begin{abstract}
Background: At present, the conversion of oils to biodiesel is predominantly carried out using chemical catalysts. However, the corresponding lipase-catalysed process has important advantages, which include mild reaction conditions and the possibility of using cheap, low quality feedstocks with a high free fatty acid content. Further increases in the efficiency of the enzymatic process are desired to make it even more attractive and suitable for large-scale applications.

Results: Herein, we present a simple and efficient two-phase lipase-catalysed system for the preparation of biodiesel in which different parameters (biocatalyst composition, ethanol concentration and the presence of additives) were optimised in order to obtain the maximum productivity starting from triolein with a high free oleic acid content. In the two-phase system, the enzyme tolerated high-ethanol concentrations, which made it possible to reach high conversions. The addition of silica particles increased the reaction rate substantially. It was suggested that such particles can catalyse acyl migration as a step to the full conversion to glycerol and biodiesel. However, in the system studied here, the effect of the particles was shown to be due to the formation of smaller and more uniform emulsion droplets leading to better mass transfer between the two phases. Particles of widely different size had positive effects, and the highest rate was obtained with silica particles derivatised with phenyl groups. The optimal conditions were applied to the solvent-free ethanolysis of rapeseed oil, and a yield of 96\% was reached in $5 \mathrm{~h}$. Under the mild conditions used, chemical catalysts were inefficient.

Conclusions: Triacylglycerol oils with a high free fatty acid content can be efficiently converted to ethyl esters using Thermomyces lanuginosus lipase as the catalyst in an aqueous/organic two-phase system. Fast mass transfer can be achieved using silica particles, which helped to decrease the size of the emulsion droplets and thus led to a more efficient process. The high-ethanol concentration tolerated by the lipase in this system made it possible to reach almost quantitative yields.
\end{abstract}

Keywords: Biodiesel, Lipase, Transesterification, Thermomyces lanuginosus, High fatty acid content, Ethanolysis, Pickering emulsion and two-phase system

\section{Background}

Biodiesel is a mixture of esters that can be produced by the transesterification of triglycerides (oils) with short-chain alcohols, obtaining glycerol as the major byproduct [1-3]. Biodiesel production has gained importance in recent years for its ability to replace fossil fuels since it can be blended with conventional diesel fuel. Additionally, its use does not require any important technical modifications on the engine, and it provides environmental benefits since it is a renewable source of energy [4]. Global biodiesel production was less than 1 billion litres in 2000, which has increased to almost 15

\footnotetext{
*Correspondence: juan.mangas@biotek.lu.se
Department of Biotechnology, Lund University, P.O. Box 124, Lund SE-221 00,

* Correspondence: juan.mangas@biotek.lu.se
Department of Biotechnology, Lund University, P.O. Box 124, Lund SE-221 00, Sweden
}

(C) 2015 Mangas-Sanchez and Adlercreutz; licensee BioMed Central. This is an Open Access article distributed under the terms of the Creative Commons Attribution License (http://creativecommons.org/licenses/by/4.0), which permits unrestricted use, distribution, and reproduction in any medium, provided the original work is properly credited. The Creative Commons Public Domain Dedication waiver (http://creativecommons.org/publicdomain/zero/1.0/) applies to the data made available in this article, unless otherwise stated. ducer, with a market share of around 55\%. This production is highly influenced by domestic fuel policy [6], and in this context, several targets have been established for the use of biodiesel in fuels [7].

Industrial biodiesel production is still mainly carried out via base-catalysed transesterification using sodium or potassium hydroxides with an excess of methanol [8-11]. Alkoxides are also often used since less water is released in the reaction. These processes present several drawbacks such as the need to remove inorganic salt in the downstream process, the high temperature required and undesirable side reactions. Also, these systems have been found to be inefficient when a high free fatty acid (FFA) content is present in the starting material [12], 
which restricts the use of conventional chemical pathways to a highly pure feedstock. For ecological and economical reasons, the development of new methodologies has attracted attention in recent years. In this context, the use of lipases may become an alternative solution [13-16]. Immobilised lipase-catalysed transesterification in the presence of an organic solvent has been studied in detail. The possibility of reusing the enzyme and the simplicity of the downstream process makes this approach attractive [17]. While the use of biocatalytic methods is well-established for the preparation of pharmaceutical products, much higher productivities are required for commodity chemicals due to the price of biocatalysts. Concerning biodiesel production, lipase immobilisation adds an extra cost to the process and partial inactivation may also occur. Therefore, the catalyst has to be reused many times in order to be economically feasible [18]. For these reasons, the use of liquid lipase preparations has attracted interest, but the optimisation of these processes is needed in order to establish them as a realistic industrial alternative.

Two-phase systems are of particular interest for reactions with both non-polar and polar substrates and products. Lipases specifically evolved for the hydrolysis of fats and oils; they are activated in biphasic mixtures in a process called interfacial activation [19]. Most lipases have a lid covering the lipophilic active site. Once the lipase comes into contact with a non-polar surface, the lid opens, exposing the lipophilic area where the active site is situated. This part is oriented towards the organic layer, such that the lipid can easily enter the active site and the hydrophilic products can diffuse into the aqueous layer. For that reason, two-phase reaction media seem to be the most suitable environment for these particular enzymes [20]. In this sense, we have recently developed an efficient methodology for the chemoenzymatic preparation of 2-monoolein and 1,2-diolein in a twophase system [21]. Nevertheless, these systems present mass transfer limitation issues, especially when working with surfactant-like species such as diacyl and monoacylglycerides (DAGs and MAGs). To overcome this limitation, the use of strategies which can favour mass transfer in the complex system is important.

In the current study, aqueous-organic two-phase systems for biodiesel production were developed. In the development work, a substrate containing triolein rich in free oleic acid was used to simulate a lowquality oil. Since the substrate contained no fatty acids other than oleic acid, it was possible to quantify all intermediate acylglycerol products accurately, thus facilitating the optimization of the system in a rational way. Finally, the best reaction conditions were also applied to the solvent-free conversion of rapeseed oil to biodiesel.

\section{Results and discussion \\ Enzyme screening}

Enzymatic ethanolysis of triglycerides (TAGs) for the preparation of biodiesel constitutes a complex system because it includes two liquid phases and several enzyme-catalysed reactions. Lipases express different specificities for each reaction involved [16], and therefore, the screening of lipases in the reaction system is important. Initially, both the organic and aqueous phase were analysed, but it was found that the amounts of acylglycerols, biodiesel and FFA in the aqueous phase were negligible. Lipases from Rhizomucor miehei and Pseudomonas fluorescens converted only small amounts of TAG under the conditions used (Figure 1). The lipase from Pseudomonas sp. converted most of the TAG, but only minor amounts of biodiesel were formed; instead, DAG,

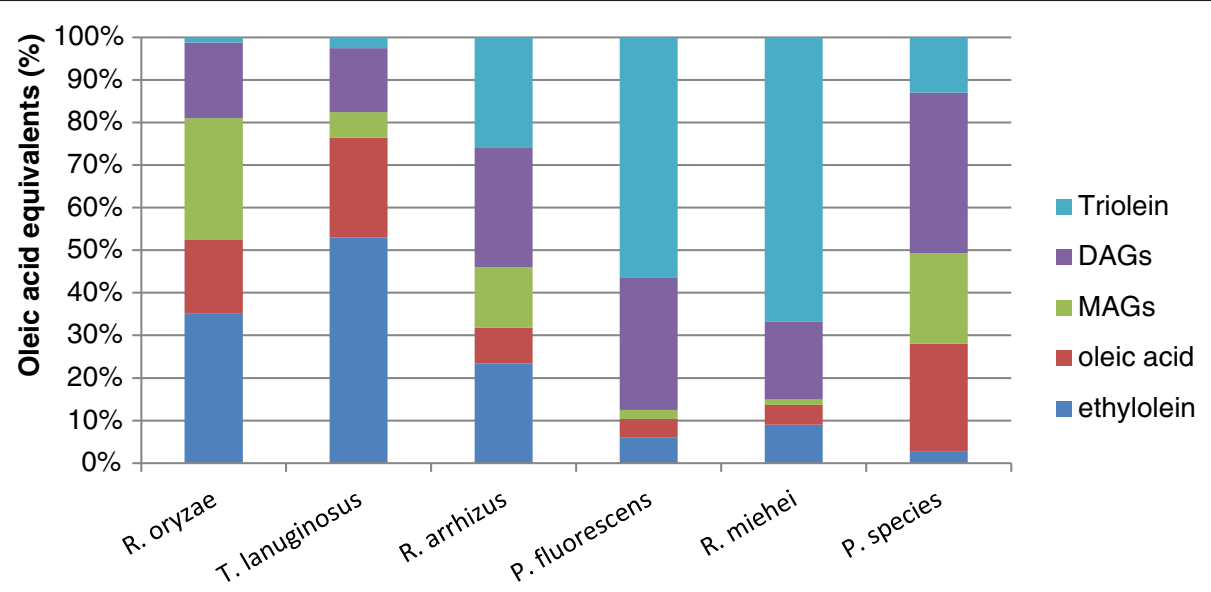

Figure 1 Product composition after $\mathbf{6} \mathbf{h}$ using different lipases. Ethanolysis of triolein catalysed by different lipases at $37^{\circ} \mathrm{C}$ and 1,000 r.p.m using $400 \mathrm{mM}$ ethanol and $75 \mathrm{mg}$ enzyme/g substrate for solid preparations and $100 \mu \mathrm{L}$ enzyme/g substrate for liquid formulations. DAGs, diacylglycerols; MAGs, monoacylglycerols. 
MAG and FFA were the main products. Rhizopus oryzae, Rhizopus arrhizus and Thermomyces lanuginosus lipases produced biodiesel yields $>23 \%$. $R$. oryzae and $R$. arrhizus lipases express strong 1,3-specificity and promoted the accumulation of high 2-MAG concentrations. T. lanuginosus lipase was efficient in converting all the acylglycerols and was found to be the most suitable biocatalyst for biodiesel preparation. Using this lipase, $97.5 \%$ conversion of TAG was reached after $6 \mathrm{~h}$, providing a $53 \%$ yield of biodiesel.

\section{Biocatalyst composition}

The biodiesel yield improved with an increasing amount of TLL up to $100 \mu \mathrm{L}$ of enzyme per gram of substrate (Figure 2). It has been shown that combinations of lipases can favour the process since different lipases have different substrate specificity $[16,22]$. As a complement to TLL, which is efficient in converting TAG, Candida antarctica lipase B (CAL-B) was chosen since this enzyme can efficiently convert DAG and MAG [16]. However, under the conditions used, the addition of CAL-B did not improve the biodiesel yield. It should be pointed out that the observed yields are higher than those obtained using immobilised TLL in a low-water system with a similar substrate (Figure 2, [16]), which shows that TLL is more efficient in biodiesel production in a two-phase system than in a pure organic medium. This agrees with previous observations that TLL is very efficient in aqueous/organic two-phase systems rather than in pure organic media compared to CAL-B [23]. However, a drawback of the two-phase system is that the high-water content causes a significant hydrolysis reaction, which competes with biodiesel formation.

\section{Effect of ethanol concentration}

In order to suppress the hydrolysis reaction and favour the alcoholysis reaction, the alcohol concentration in the reaction mixture can be increased, although it is known that alcohols can also inhibit and inactivate lipases $[24,25]$. A range of ethanol concentrations between $400 \mathrm{mM}$ and $3 \mathrm{M}$ was tested. The initial rate was highest at ethanol concentrations of 1.6 and $2.0 \mathrm{M}\left(0.17 \mu \mathrm{mol} \mathrm{min}{ }^{-1} \mu \mathrm{L}^{-1}\right.$ enzyme), while after $6 \mathrm{~h}$, the highest biodiesel yield was observed with $2.5 \mathrm{M}$ ethanol (Figure 3). After $24 \mathrm{~h}$, equilibrium was reached in most cases, and the yield increased with an increasing ethanol concentration, with the exception of the highest one (Table 1). It should be noted that the FFA concentrations decreased towards the end of the reaction, which indicates that the FFA formed under kinetic control was esterified in the later part of the reaction, when equilibrium was approached. An additional experiment was conducted using the same experimental set-up with $100 \mathrm{mM}$ oleic acid and $2 \mathrm{M}$ ethanol as the substrates. After just $1 \mathrm{~h}, 95 \%$ conversion was observed, showing that the enzyme was able to convert FFA into biodiesel efficiently. It seemed that the enzyme tolerated high-ethanol concentrations in the two-phase system quite well and a concentration of $2 \mathrm{M}$ was chosen for the rest of the experiments.

\section{Effects of added particles}

Due to the high 1,3-specificity expressed by many lipases, including TLL, the accumulation of 2-MAG is expected to constitute a bottleneck in the process. To promote the overall conversion to glycerol and biodiesel, the addition of substances able to catalyse the isomerisation of 2-MAG to the thermodynamically more stable 1 (3)-MAG, which is a better substrate for lipases, has been applied successfully. In a typical example, soybean oil is converted to biodiesel using a mixture of immobilised

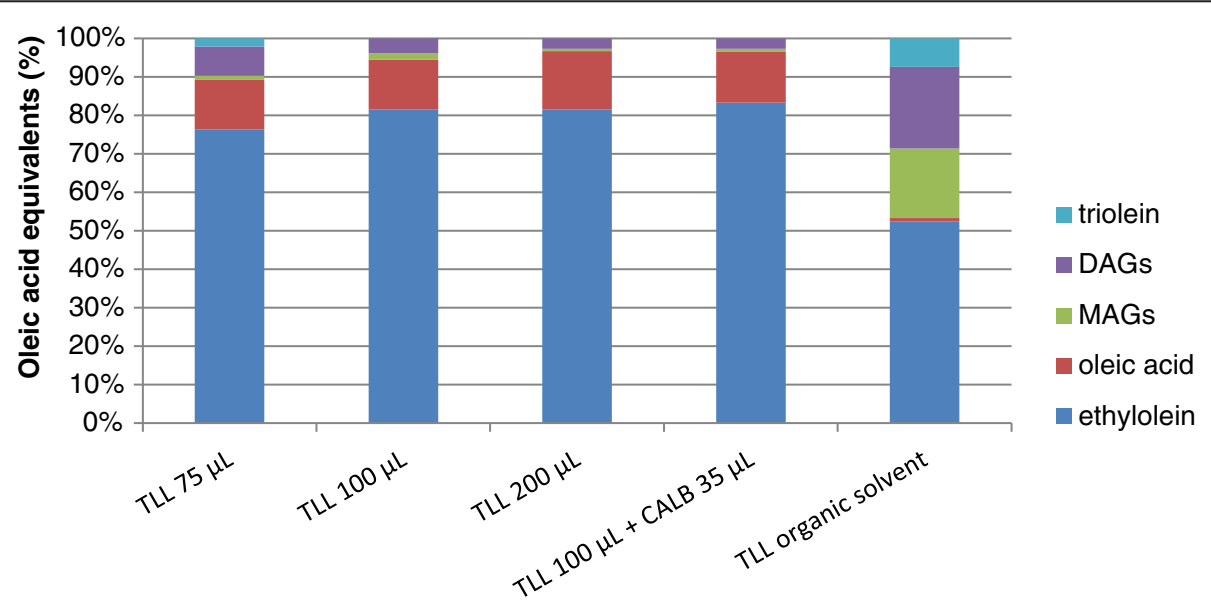

Figure 2 Product composition after $\mathbf{2 4}$ h using different enzyme amounts and combinations. Ethanolysis of triolein catalysed by different lipase types and amounts at $37^{\circ} \mathrm{C}, 1,000$ r.p.m. and $400 \mathrm{mM}$ ethanol concentration. DAGs, diacylglycerols; MAGs, monoacylglycerols; TLL, T. lanuginosus lipase. 


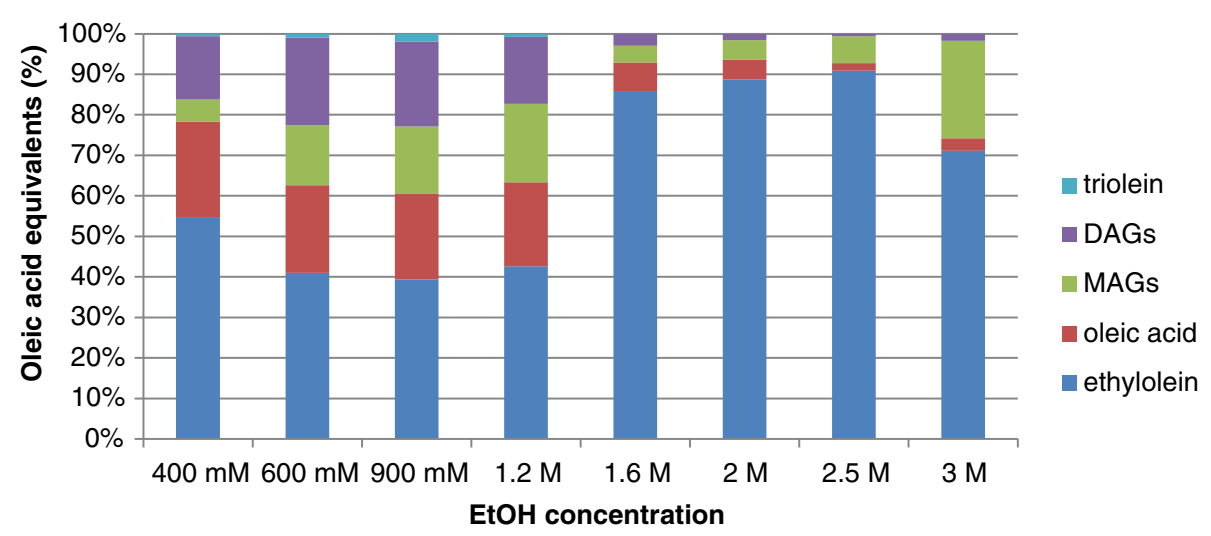

Figure 3 Product composition after $6 \mathrm{~h}$ using different ethanol concentrations. Ethanolysis of triolein catalysed by TLL lipase using different ethanol concentrations and $100 \mu \mathrm{L}$ of TLL/g substrate at $37^{\circ} \mathrm{C}$ and 1,000 r.p.m. DAGs, diacylglycerols; MAGs, monoacylglycerols.

lipase and silica gel as the catalyst [26]. Another approach is to immobilise the lipase on an anion exchange resin, which works both as a support for the lipase and as an acyl migration catalyst [27]. Since silica is the most commonly used acyl migration catalyst, the addition of $4 \% \mathrm{w} / \mathrm{v}$ silica (35- to 70- $\mu \mathrm{m}$ particle size) was evaluated in the reaction system used in the present study; it was found to increase the rate of biodiesel formation significantly. In order to confirm that it was acyl migration that caused the increased conversion rate, 2-monoolein was synthesised separately and its isomerisation to 1(3)-monoolein was studied under different conditions. Acyl migration was promoted by silica in pure heptane, in agreement with previous observations (Figure 4). However, surprisingly enough, no acyl migration was observed in the water/heptane two-phase system in the presence or absence of silica (Figure 4). In order to determine the mechanism of the silica-induced increase in the biodiesel production rate, the reaction mixtures were subjected to microscopic investigation. It was found that the presence of silica particles caused the formation of an emulsion with smaller and more uniform droplets than in the absence of silica particles (Figure 5). It is likely that the increased interfacial area caused the observed increase in the reaction rate, by speeding up the mass transfer of substrates and products between the phases. Alternatively, the increased rate could have been due to increased interfacial activation of TLL due to the increased interfacial area.

It is known that small solid particles can act as amphiphilic molecules, adsorbing on droplets and preventing flocculation and coalescence and thus creating so-called Pickering emulsions [28-32]. However, this requires much smaller particles and more power input than the shaking that was used in the present study. To further study the effects of particles on the studied biodiesel process, the addition of smaller silica particles was evaluated. Furthermore, since it has been shown that not only the size but also the surface character of the particles can affect the stability of the emulsion [33], all sizes of silica particles were evaluated in a phenyl-derivatised form as well. All types of particles increased the biodiesel formation rate and the phenyl-modified particles were somewhat more efficient (Figure 6). After a 3-h reaction time, all acylglycerols had been converted in the reactions involving Phenyl 35-70 and Phenyl 0.007 (Figure 7), and in the continued reaction, a further increase in yield was observed due to esterification of the originally formed FFA. After $6 \mathrm{~h}$, yields over $95 \%$ were obtained regardless of the particle size and hydrophobic character.

All particles caused the formation of emulsions with a similar droplet size (Figure 5). Since the effect was observed not only with nanoparticles, but also with

Table 1 Product composition using different amounts of ethanol

\begin{tabular}{|c|c|c|c|c|c|c|c|c|}
\hline & $400 \mathrm{mM}$ & $600 \mathrm{mM}$ & $900 \mathrm{mM}$ & $1.2 \mathrm{M}$ & $1.6 \mathrm{M}$ & $2 M$ & $2.5 \mathrm{M}$ & $3 M$ \\
\hline Ethylolein & $72.1 \pm 2.4$ & $73.3 \pm 3.1$ & $78.5 \pm 2.2$ & $91.0 \pm 2.7$ & $98.3 \pm 1.4$ & $98.0 \pm 1.6$ & $99.7 \pm 0.2$ & $99.4 \pm 0.3$ \\
\hline Oleic acid & $24.6 \pm 2.2$ & $15.5 \pm 0.7$ & $11.7 \pm 2.1$ & $5.9 \pm 3.6$ & $1.7 \pm 1.4$ & $2.0 \pm 1.6$ & $0.3 \pm 0.2$ & $0.6 \pm 0.3$ \\
\hline MAGs & $0.8 \pm 0.2$ & $3.5 \pm 0.7$ & $4.7 \pm 0.7$ & $3.1 \pm 0.6$ & 0 & 0 & 0 & 0 \\
\hline DAGS & $2.5 \pm 0.8$ & $7.7 \pm 0.6$ & $5.1 \pm 0.1$ & 0 & 0 & 0 & 0 & 0 \\
\hline Triolein & 0 & 0 & 0 & 0 & 0 & 0 & 0 & 0 \\
\hline
\end{tabular}

Product composition (oleic acid equivalents, \%) after $24 \mathrm{~h}$ at $37^{\circ} \mathrm{C}$ and 1,000 r.p.m. using different ethanol concentrations and $100 \mu \mathrm{L}$ of TLL/g substrate. DAGs, diacylglycerols; MAGs, monoacylglycerols. 


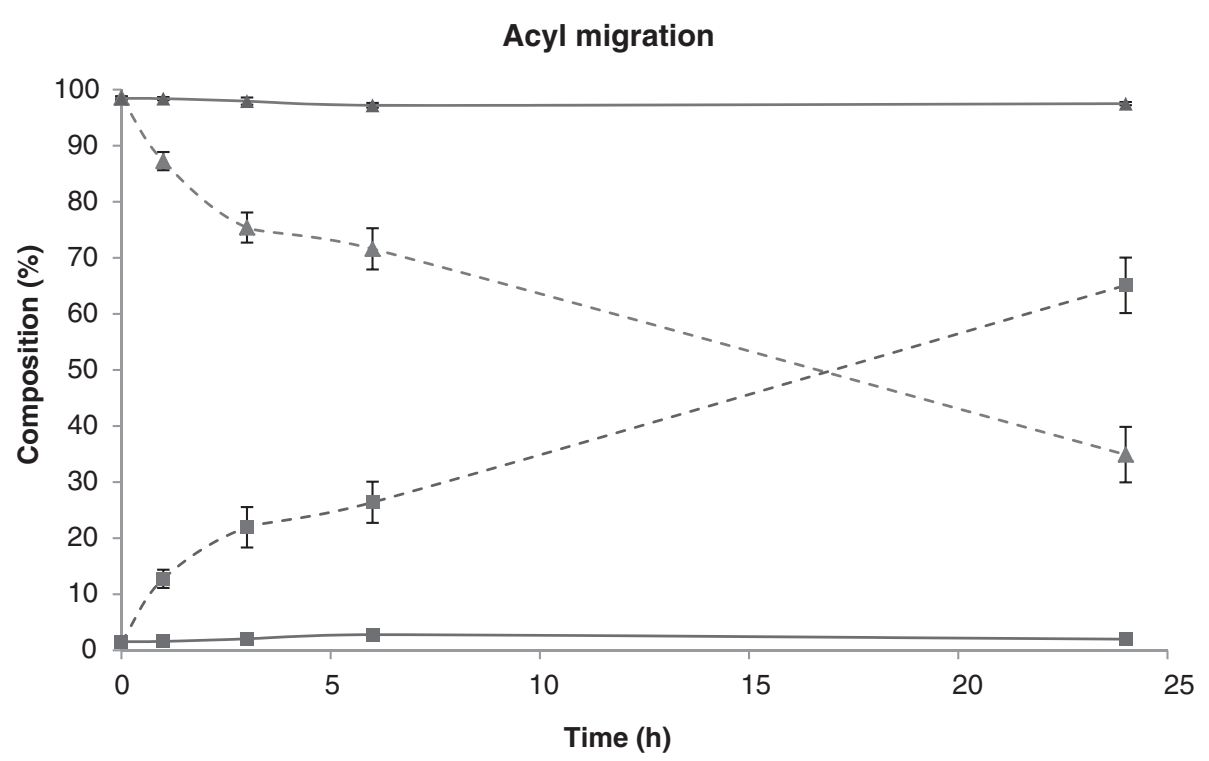

Figure 4 Acyl migration study. The 2-monoolein (triangles) and 1-monoolein (squares) as a function of time using $4 \% \mathrm{~W} / \mathrm{V}$ silica gel (35- to 70- $\mu \mathrm{m}$ particle size) as acyl migration promoter in the two-phase system ( $n$-heptane/water 20\%, solid lines) and in pure $n$-heptane (dotted lines).

particles much larger than the liquid droplets, it is clear that this is not a typical example of a Pickering emulsion. Furthermore, the power input was most probably not high enough to create a Pickering emulsion, which normally requires ultrasound, high-pressure homogenizers or other devices producing high-shear stress [31].
However, our emulsions induced by particles without the use of high-energy emulsification equipment may be quite useful for biodiesel production because of the considerably increased reaction rate. The fact that slightly higher rate enhancement was observed with phenyl-derivatised silica particles indicates that an additional activation

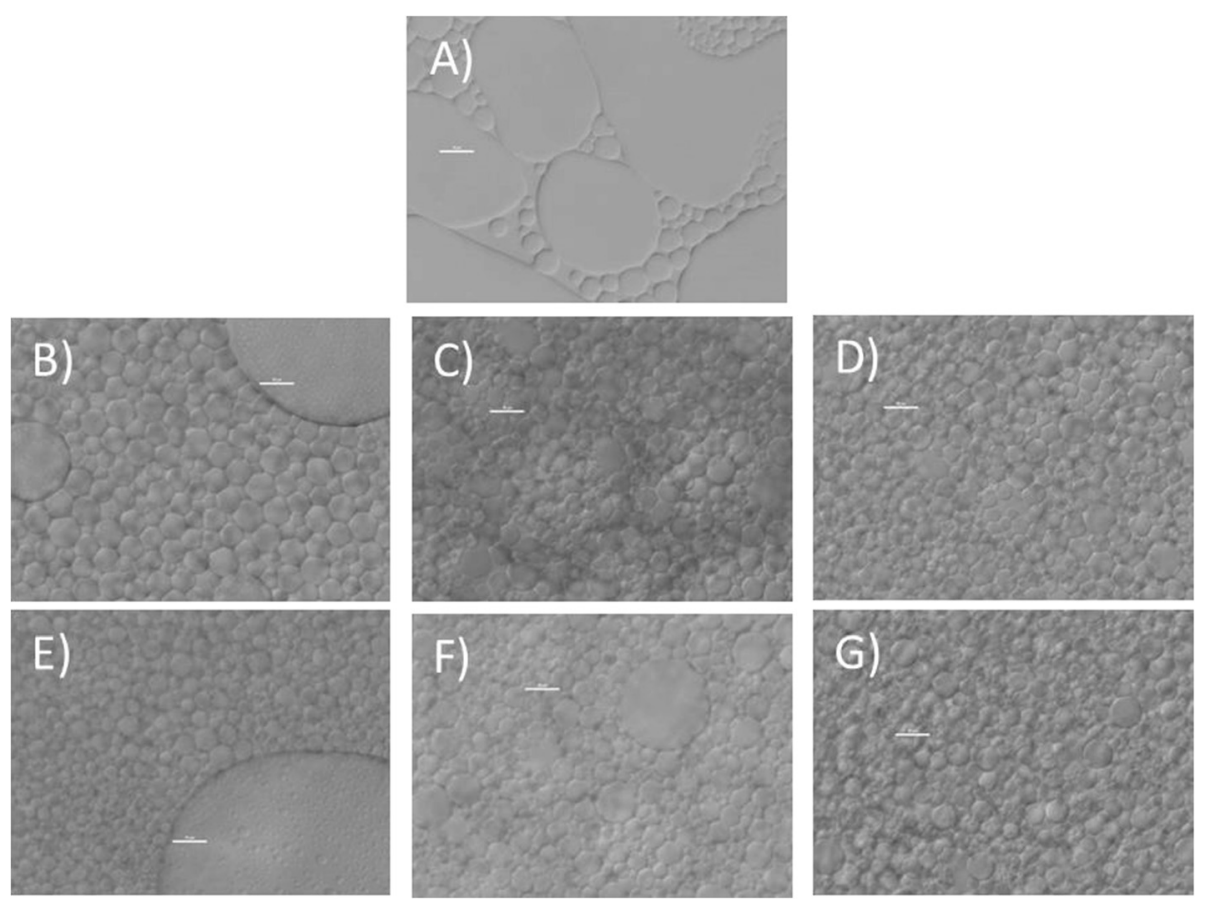

Figure 5 Emulsion pictures using different conditions. (A) No additive, (B) non-modified silica gel 35 to $70 \mu \mathrm{m}$, (C) non-modified silica gel 0.2 to $0.3 \mu \mathrm{m}$, (D) non-modified silica gel $0.007 \mu \mathrm{m}$, (E) phenyl silica gel 35 to $70 \mu \mathrm{m}$, (F) phenyl silica gel 0.2 to $0.3 \mu \mathrm{m}$, (G) phenyl silica gel $0.007 \mu \mathrm{m}$. Used was $4 \% \mathrm{w} / \mathrm{V}$ of the different additives and $100 \mu \mathrm{L}$ of TLL/g substrate. Scale bars: $10 \mu \mathrm{m}$. The large structures in (B) and (E) are silica particles. 


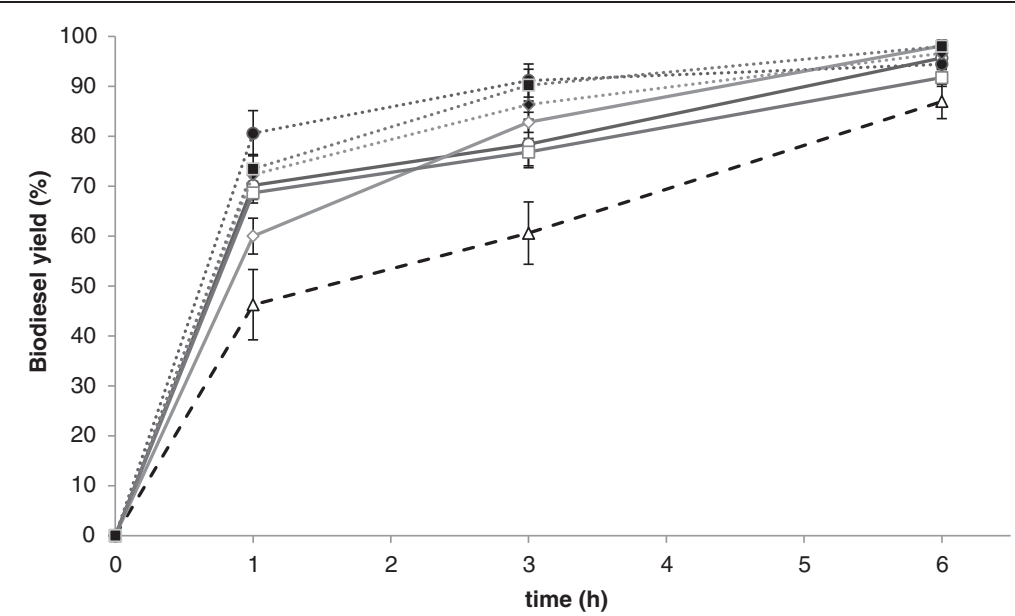

Figure 6 Biodiesel batch production (yield) using different solid particles. No additive (dashed line), phenyl-modified silicas (dotted lines, closed symbols) and non-modified silicas (solid lines, open symbols). Particle size: 35 to $70 \mu \mathrm{m}$ (circles), 0.2 to $0.3 \mu \mathrm{m}$ (diamonds) and $0.007 \mu \mathrm{m}$ (squares). Used was $4 \% \mathrm{w} / \mathrm{V}$ of the different additives and $100 \mu \mathrm{L}$ of TLL/g substrate.

mechanism might have been in operation. It is possible that the lipase to some extent was adsorbed on the hydrophobic surface of the derivatised particles, thereby causing opening of the lid and interfacial activation, as previously observed after adsorption of lipases on hydrophobic materials. However, since almost equal activation was observed with underivatised silica particles, it appears that the main rate-enhancing effect of the particles was due to the reduction of droplet size.

\section{Comparison with chemical catalysis}

Methanolysis of vegetable oils in the presence of a homogeneous base catalyst is nowadays the dominant process in industrial biodiesel production. A comparison between the biocatalytic method developed in this work and the homogeneous catalyst under the same conditions (pressure, temperature and time) was carried out. The most common acid/base homogeneous catalysts used in industry, for example, $\mathrm{NaOH}, \mathrm{NaOMe}$, $\mathrm{KOH}$ and $\mathrm{H}_{2} \mathrm{SO}_{4}$ were included in the comparison at a concentration of $2 \%(w / v$ or $v / v)$. No reaction was detected in any case after $24 \mathrm{~h}$. These results can be explained by the high free fatty acid content of the starting material and also by the mild reaction conditions used.

\section{Biodiesel preparation from rapeseed oil}

Once the optimised conditions were set, these were applied to a real feedstock material. Rapeseed oil was selected as the substrate, and the reaction was carried out under solvent-free conditions, starting from $300 \mathrm{mg}$ of oil, $0.4 \mathrm{~mL}$ of water, $8 \mathrm{mg}$ of phenyl silica (35- to 70$\mu \mathrm{m}$ particle size) and $100 \mu \mathrm{L}$ of enzyme/g substrate at

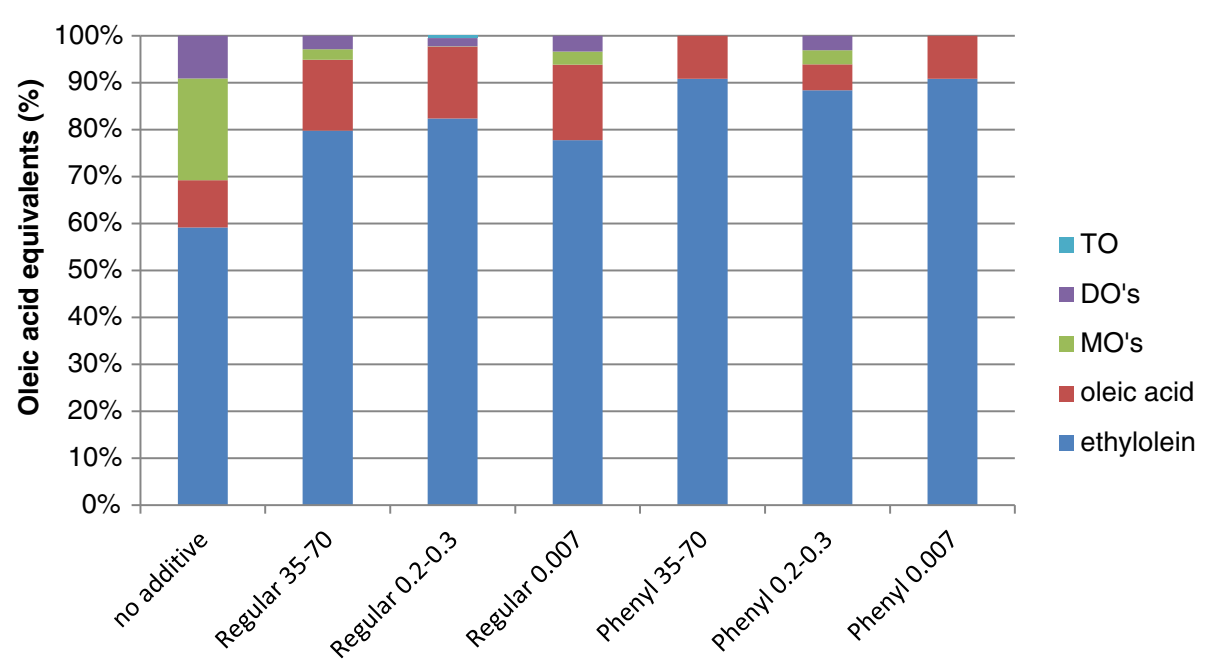

Figure 7 Product composition after $\mathbf{3}$ h using different silica gels. Ethanolysis of triolein catalysed by TLL using regular silica or phenyl silica with different particle size (given in microns) as additives and $100 \mu \mathrm{L}$ of TLL/g substrate at $37^{\circ} \mathrm{C}$ and 1,000 r.p.m. DO, dioleins; MO, monoolein; TO, triolein. 
$37^{\circ} \mathrm{C}$ and 1,000 r.p.m. The process was monitored by GC, and after $5 \mathrm{~h}, 96 \%$ biodiesel yield was observed, with 2\% MAGs and 2\% DAGs remaining.

\section{Conclusions}

We have developed a very effective method for the enzymatic preparation of biodiesel, which is also useful for oils with a high free fatty acid content. The method uses a liquid formulation of $T$. lanuginosus lipase in an aqueous/organic two-phase system. The enzyme has shown an excellent tolerance to ethanol, which not only made the process faster but also allowed for the total conversion of the free fatty acid into biodiesel with a shortreaction time. Triacylglycerol conversion was very fast, while the main bottleneck in the process was the conversion of DAG and MAG. The use of solid silica particles led to changes in the emulsion structure which permitted a larger surface area in the interphase, overcoming mass transfer limitations and thus increasing the rate of the process. Surprisingly, the silica particles did not cause acyl migration as observed in other biodiesel production systems. The emulsion-enhancing effects of particles of widely varying size has not been described before, at least not in the biodiesel production field, and is clearly different from the creation of Pickering emulsions, which requires small particles and high-energy input. This work demonstrates the potential of liquid lipase preparations for biodiesel production starting from high free fatty acid feedstocks such as waste oils. Under the best conditions, almost quantitative yields were achieved after only $6 \mathrm{~h}$ of reaction. These results constitute a good starting point for efficient and cheap biodiesel production, and the next step would be to adapt the methodology to readily available cheap waste oils.

\section{Materials and methods Chemicals}

Lipases from T. lanuginosus (2,200 U/mL, Sigma), $R$. oryzae (Aldrich, product number 80612), R. arrhizus (Sigma, product number 62305), P. fluorescens (Aldrich), R. miehei (Sigma), Pseudomonas species (Aldrich) and Candida antarctica lipase B (Sigma), p-nitrophenyl butyrate and silica gels of different particle sizes (silica gel 35 to $79 \mu \mathrm{m}$, silica fumed 0.2 to $0.3 \mu \mathrm{m}$ and silica fumed $0.007 \mu \mathrm{m}$ ) were obtained from Sigma-Aldrich Co. (Steinheim, Germany); cyclohexane and tetradecane were purchased from Merck (Darmstadt, Germany); $n$-heptane, ethanol (99.5\%) from VWR (Stockholm, Sweden); and $\mathrm{N}$-methyl- $\mathrm{N}$-trimethylsilylheptafluorobutyramide (MSHFBA, Machery-Nagel) from ScantecLab (Partille, Sweden). Triolein was obtained from Larodan Fine Chemicals (Malmö, Sweden), perfluorodecyltriethoxysilane from Alfa Aesar and phenyltrimethoxysilane and $n$-octyltriethoxysilane were acquired from Acros Organics. Rapeseed oil was purchased in a local supermarket.
Other chemicals were of analytical grade. A high oleic acid content starting material was used in order to simulate a low-quality oil. The composition (molar ratio) of the starting material was 54\% triolein, 24\% DAGs and 22\% oleic acid.

\section{GC analysis}

The samples were analysed by GC using a Varian gas chromatograph (430-GC-FID, Agilent Technologies Inc., Santa Clara, CA) equipped with a flame-ionisation detector and a FactorFour ${ }^{\mathrm{Tm}}$ capillary column $(\mathrm{VF}=1 \mathrm{~ms}$, length $15 \mathrm{~m}$ and ID $250 \mu \mathrm{m}$, Varian, Agilent Technologies Inc., Santa Clara, CA). Helium was used as the carrier gas, and the temperature of both the detector and injector was $350^{\circ} \mathrm{C}$. The starting temperature of the column was $180^{\circ} \mathrm{C}$. This was maintained for $2.5 \mathrm{~min}$, then increased by $10^{\circ} \mathrm{C} / \mathrm{min}$ to a temperature of $340^{\circ} \mathrm{C}$ and was then maintained for $26 \mathrm{~min}$.

Samples were withdrawn from the organic phase and derivatised by silylation by adding an equal volume of MSHFBA and incubating the mixture at room temperature for $30 \mathrm{~min}$. An equal volume of dry ethanol was then added to stop the reaction. The samples were diluted 30 times with an internal standard solution (tetradecane) in cyclohexane to obtain a sample in which the final solution of tetradecane was $9 \mathrm{mM}$, suitable for GC. The concentrations of the compounds were calculated using response factors obtained from a standard curve.

\section{Alcoholysis reactions}

The standard reaction conditions were $265 \mathrm{mg}$ of the starting material (mainly triolein, see the section on 'Chemicals') in $1.6 \mathrm{~mL}$ of $n$-heptane with different ethanol concentrations in a $4.5-\mathrm{mL}$ vial with septum. The reaction was started by adding the biocatalyst (different amounts) in $0.4 \mathrm{~mL}$ of $\mathrm{H}_{2} \mathrm{O}$. The reactions were carried out in a thermomixer at 1,000 r.p.m. Samples from the organic phase were regularly withdrawn with a Hamilton syringe and analysed by GC. The concentration of each component was calculated as a percentage of the initially available oleic acid equivalents, bearing in mind that diacylglycerols and triacylglycerols contain two and three fatty acid moieties, respectively. All experiments were carried out in duplicate. Error bars are omitted in some charts in order to have a better understanding of the results since standard deviations are in all cases below $4 \%$.

\section{Silica modification}

Silica gels of different particle sizes were modified with phenyl moieties in order to increase their hydrophobicity. The most often used method for preparing hydrophobic inorganic support materials is to silanise the support. To that purpose, $200 \mathrm{mg}$ of silica (30- to 75-, 
0.2 - to 0.3 - and $0.007-\mu \mathrm{m}$ particle sizes) were suspended in $1.5 \mathrm{~mL}$ of dry toluene, and the mixture was kept at $130^{\circ} \mathrm{C}$ for $6 \mathrm{~h}$. Then, $0.5 \mathrm{~mL}$ of phenylmethoxysilane was added, and the mixture was stirred overnight at $70^{\circ} \mathrm{C}$. The suspension was cooled and the solvent was removed by decantation. The preparation was washed with fresh toluene, and MTBE and was finally air-dried at room temperature.

\section{Microscopy}

The structure of the emulsions was studied by interference microscopy. Images were taken using a Nikon Optishot-2 microscope at $\times 400$ magnification with Digital Sight DS $2 \mathrm{Mv}$ camera and processed using NIS-elements 3.1D.

\section{Abbreviations \\ CAL-B: Candida antarctica lipase B; DAGs: diacylglycerols; GC: gas chromatography; MAGs: monoacylglycerols; MSHFBA: N-methyl-N- trimethylsilylheptafluorobutyramide; MTBE: methyl tert-butyl methyl ether; TLL: Thermomyces lanuginosus lipase.}

\section{Competing interests}

The authors declare that they have no competing interests.

\section{Authors' contributions}

JMS designed the study, performed the experiments, analysed the results and drafted the manuscript. PA participated in the design of the study and commented and revised the manuscript. Both authors approved the final manuscript.

\section{Acknowledgements}

This work was financially supported by the Swedish Research Council Formas (Grant no. 213-2012-820)

Received: 14 January 2015 Accepted: 26 March 2015

Published online: 03 April 2015

\section{References}

1. Atadashi IM, Aroua MK, Aziz AA. Biodiesel separation and purification: a review. Renew Energy. 2011;36:437-43.

2. Fjerbaek L, Christensen KV, Norddahl B. A review of the current state of biodiesel production using enzymatic transesterification. Biotech Bioeng. 2009;102:1298-312.

3. Saleh J, Tremblay AY, Dubé MA. Glycerol removal from biodiesel using membrane separation technology. Fuel. 2010;89:2260-6.

4. Yusuf NNAN, Kamarudin SK, Yaakub Z. Overview on the current trends in biodiesel production. Energy Convers Manag. 2011;52:2741-51.

5. Sorda G, Banse M, Kemfert C. An overview of biofuel policies across the world. Energy Policy. 2010;38:6977-88.

6. Hervé G, Agneta F, Yves. D. Biofuels and world agricultural markets: outlook for 2020 and 2050, Economic effects of biofuel production. Dr. Marco Aurelio Dos Santos Bernardes (Ed.); 2011. ISBN: 978-953-307-178-7, InTech, doi: 10.5772/20581. Available from: http://www.intechopen.com/books/economic-effects-of-biofuel-production/biofuels-and-world-agricultural-marketsoutlook-for-2020-and-2050.

7. Bozbas K. Biodiesel as an alternative motor fuel: production and policies in the European Union. Renew Sustan Energ Rev. 2008;12:542-52.

8. Srivastava A, Prasad R. Triglycerides-based diesel fuels. Renew Sustan Energ Rev. 2000;4:111-33.

9. Zhang Y, Dube MA, Mclean DD, Kates M. Biodiesel production from waste cooking oil: 1. Process design and technological assessment. Bioresour Technol. 2003;89:1-16.

10. Meher LC, Sagar DV, Naik SN. Technical aspects of biodiesel production by transesterification-a review. Renew Sustan Energ Rev. 2006;10:248-68.

11. Stamenkovic OS, Velickovic AV, Veljkovic VB. The production of biodiesel form vegetable oils by ethanolysis: current state and perspectives. Fuel. 2011;90:3141-55.
12. Atadashi IM, Aroua MK, Abdul Aziz AR, Sulaiman NMN. Production of biodiesel using high free fatty acid feedstocks. Renew Sustan Energ Rev. 2012;16:3275-85

13. Narwal SK, Gupta R. Biodiesel production by transesterification using immobilized lipase. Biotechnol Lett. 2013;35:479-90.

14. Ranganathan SV, Narasimham SL, Muthukumar K. An overview of enzymatic production of biodiesel. Biores Technol. 2008;99:3975-81.

15. Bajaj A, Lohan P, Jha PN, Mehrotra R. Biodiesel production through lipase catalyzed transesterification: an overview. J Mol Catal B Enz. 2010;62:9-14.

16. Šinkūnienè $D$, Adlercreutz $P$. Effects of regioselectivity and lipid class specificity of lipases on transesterification, exemplified by biodiese production. J Am Oil Chem Soc. 2014;91:1283-90.

17. Nordblad MVT, Silva L, Nielsem PM, Woodley JM. Identification of critical parameters in liquid enzyme-catalyzed biodiesel production. Biotech Bioeng. 2014;111:2446-53.

18. Tufvesson P, Lima-Ramos J, Nordblad M, Woodley JM. Guidelines and cost analysis for catalyst production in biocatalytic processes. Org Proc Res Dev. 2011;15:266-74.

19. Drauz K, Gröger H, May O. Enzyme catalysis in organic synthesis. 1st ed. Weinheim: Wiley-VCH; 2012.

20. Faber K. Biotransformations in organic chemistry. 6th ed. Berlin: Springer; 2011.

21. Mangas-Sánchez J, Serrano-Arnaldos M, Adlercreutz P. Effective and highly selective lipase-mediated synthesis of 2-monoolein and 1,2-diolein in a two-phase system. J Mol Catal B Enz. 2015;112:9-14.

22. Huang $Y$, Zheng $H$, Yan YJ. Optimization of lipase-catalyzed transesterification of lard for biodiesel production using response surface methodology. Appl Biochem Biotech. 2010;160:504-15.

23. Salis A, Svensson I, Monduzzi M, Solinas V, Adlercreutz P. The atypical lipase B from Candida antarctica is better adapted for organic media than the typical lipase from Thermomyces lanuginosa. Biochim Biophys Acta. 2003;1646:145-51.

24. Shimada Y, Watanabe Y, Sugihara A, Tominaga Y. Enzymatic alcoholysis for biodiesel fuel production and application of the reaction to oil processing. J Mol Catal B: Enzym. 2002;17:133-42.

25. Adlercreutz P. Immobilisation and application of lipases in organic media. Chem Soc Rev. 2013;42:6406-36.

26. Du W, Xu YY, Liu DH, Li DH. Study on acyl migration in immobilized lipozyme TL-catalyzed transesterification of soybean oil for biodiesel production. J Mol Catal B: Enzym. 2005;37:68-71.

27. Wang YD, Shen XY, Li ZL, Li X, Wang F, Nie XA, et al. Immobilized recombinant Rhizopus oryzae lipase for the production of biodiesel in solvent free system. Journal of Molecular Catalysis B-Enzymatic. 2010;67:45-51.

28. Binks BP, Lumsdon SO. Influence of particle wettability on the type and stability of surfactant-free emulsions. Langmuir. 2000;16:8622-31.

29. Dickinson E. Food emulsions and foams: stabilization by particles. Current Opinion in Colloid and Interface Science. 2010;15:40-9.

30. Binks BP. Particles as surfactants-similarities and differences. Current Opinion in Colloid and Interface Science. 2002;7:21-41.

31. Chevalier Y, Bolzinger M-A. Emulsions stabilized with solid nanoparticles: Pickering emulsions. Colloids and Surfaces A: Physicochem Eng Aspects. 2013:439:23-34.

32. Wu C, Bai S, Ansorge-Schumacher MB, Wang D. Nanoparticle cages for enzyme catalysis in organic media. Adv Mater. 2011;23:5694-9.

33. Aveyard R, Binks BP, Clint JH. Emulsions stabilised solely by colloidal particles. Adv Colloid Interface Sci. 2003;100-102:503-46.

\section{Submit your next manuscript to BioMed Central and take full advantage of:}

- Convenient online submission

- Thorough peer review

- No space constraints or color figure charges

- Immediate publication on acceptance

- Inclusion in PubMed, CAS, Scopus and Google Scholar

- Research which is freely available for redistribution 